\title{
As definições de "gênero lírico" nos livros didáticos: problematizações e possibilidades quanto à formação de leitores
}

\author{
Caroline Dambrozio Guerra* \\ Marcus De Martini**
}

\section{Resumo}

Neste artigo, realizamos um levantamento dos conceitos de "gênero lírico" presentes nos livros didáticos de Língua Portuguesa selecionados no Programa Nacional de Livro Didático (PNLD), na edição de 2018. Tendo em vista as dificuldades de abordagem da leitura de poemas em sala de aula, um dos objetivos deste texto é verificar em que medida a problemática da conceituação de lírica interfere negativamente - na própria leitura de textos literários em sala de aula, ao apresentar conceitos teóricos que não se fundamentam na prática da leitura de textos selecionados. Dessa forma, ao recuperarmos a escolarização da poesia e ao percebermos quais características contribuem para a permanência de seu conturbado ensino, propomos, de maneira sintética, uma possibilidade de abordagem didática que busca amenizar as dificuldades da formação de leitores literários de poesia nas escolas.

Palavras-chave: Escolarização da poesia; gênero lírico; leitura; livros didáticos.

\section{Introdução}

Muito poucos livros lidos na escola são de poesia. A relação entre a leitura de poesia

e a escola tem uma história particular

de amor e desamor. Por um lado, podem tomar-se os poemas como unidades de sentido, o que tem a grande vantagem de serem curtos, e por isso poderão ser lidos, recitados e analisados em uma só aula. Por outro lado, têm a desvantagem de que sua apresentação 'como livros' dificilmente atrairá a leitura autônoma das crianças ou dará um objetivo claro ao ensino dos professores. (COLOMER, 2007, p. 172-173).

* Graduada no curso de Licenciatura em Letras - Português pela Universidade Federal de Santa Maria (UFSM) e aluna do curso de Mestrado em Letras, na área de Estudos Literários, na mesma instituição. E-mail: carolinedgg@outlook.com

** Doutor em Estudos Literários pela Universidade Federal de Santa Maria (UFSM), professor associado junto ao Departamento de Letras Vernáculas e ao Programa de Pós-graduação em Letras da mesma instituição. E-mail: marcusdemartini@gmail.com

Data de submissão: abr. 2021 - Data de aceite: jul. 2021 http://dx.doi.org/10.5335/rdes.v17i2.11409 
Ao nos colocarmos em um lugar de encontro entre duas questões bastante caras ao ensino de literatura - a tripartição clássica dos gêneros literários em épico, lírico e dramático, enquanto um conhecimento já escolarizado, e o universo dos livros didáticos -, propomos, neste trabalho, uma análise de como a problemática da definição de lírica se faz presente no universo escolar, por meio de recortes ilustrativos dos livros didáticos de Língua Portuguesa selecionados no Programa Nacional do Livro Didático (PNLD), na edição de 2018. Além disso, procuramos problematizar o reflexo dessa abordagem conceitual no próprio ato da leitura literária em sala de aula, apontando as consequentes dificuldades interpretativas que ela acarreta e propondo, sumariamente, alguns caminhos e possibilidades que vão ao encontro da superação desses entraves.

No horizonte da problematização envolvendo o "gênero lírico", interessa-nos menos sua conceituação em relação à tríade tradicional de classificação dos gêneros literários - lírico, épico e dramático - e mais a tensão interna de conceituação do próprio gênero. Para tanto, nosso olhar recupera, de forma breve, uma visão histórica da trajetória do pensamento sobre o "gênero lírico", principalmente em sua presença em ambientes didáticos de ensino e aprendizagem escolares. Já em relação ao livro didático, ambientamos sua materialidade, para além de um ob- jeto de cunho cultural, social, ideológico, instrucional, político (entre outros adjetivos aqui cabíveis), na relação dialógica com a Teoria da Literatura, entendendo esta como um conjunto de manifestações teóricas que, de uma forma ou de outra, refletiram e teorizaram sobre os "gêneros literários”, não obstante a forma como entenderam o conceito.

Nesse sentido, inserimo-nos em um contexto de contato, principalmente, entre a História, a Literatura e a Educação, dialogando com tais áreas e tendo, como ponto de interesse comum, a compreensão da problemática acerca da escolarização de um saber (conforme SOARES, 2004). Se, desde o início, já colocamos esse ponto como uma problemática, resta-nos, então, apresentar alguns possíveis caminhos para amenizá-la. Isso será realizado por meio da apresentação de uma abordagem didática, o que será delineado ao final deste texto.

Vale pontuar, ainda, que nosso interesse em mapear a abordagem da tripartição clássica dos gêneros literários nesses livros, mais especificamente do "gênero lírico", está ancorada, além de outros fatores, na forma como tais conceitos são referenciados na Base Nacional Comum Curricular (BNCC) (BRASIL, 2018). Teoricamente, há diversas correntes que, tanto no âmbito da Linguística quanto da Teoria da Literatura, discutem e sistematizam conceitos como, por exemplo, os de gêneros textuais, gêneros 
discursivos e gêneros literários. No entanto, embora, a nível acadêmico, essas abordagens sejam bastante abrangentes e promissoras em seus sistemas teóricos, elas acabam chegando de forma diferenciada (desorganizada) à escola e aos professores de nível médio.

Para exemplificar essa questão, seguimos com o exemplo da BNCC e com as diversas referências a essas nomenclaturas encontradas na área de Linguagens e suas Tecnologias. Primeiramente, é importante evidenciar que essa área concentra-se em quatro componentes específicos: Arte, Educação Física, Língua Inglesa e Língua Portuguesa. Dessa forma, a tradicional divisão curricular entre as disciplinas de Língua Portuguesa e Literatura não é mais ancorada no novo documento, uma vez que se preza pela interdisciplinaridade de competências e habilidades dentro da área e em cada componente. Tem-se, então, o componente de Língua Portuguesa como o espaço característico para o trabalho com o campo artístico-literário, que envolve, principalmente, as manifestações literárias.

No decorrer das apresentações e descrições desse componente, existem nomenclaturas diferentes para se referir às diversas manifestações textuais com as quais temos contato socialmente. Quando o texto faz referência ao componente de maneira mais geral, costuma utilizar "gêneros do discurso/gêneros textuais", como mostra o exemplo a seguir:
[...] a consolidação do domínio de gêneros do discurso/gêneros textuais já contemplados anteriormente e a ampliação do repertório de gêneros, sobretudo dos que supõem um grau maior de análise, síntese e reflexão (BRASIL, 2018, p. 499, grifo nosso).

Posteriormente, quando segue descrevendo as abordagens mais amplas desse componente, como no caso da esfera "Todos os campos da ação social", o documento segue nessa mesma linha de nomenclatura:

(EM13LP01) Relacionar o texto, tanto na produção como na leitura/ escuta, com suas condições de produção e seu contexto sócio-histórico de circulação (leitor/audiência previstos, objetivos, pontos de vista e perspectivas, papel social do autor, época, gênero do discurso, etc.), de forma a ampliar as possibilidades de construção de sentidos e de análise crítica e produzir textos adequados a diferentes situações. (BRASIL, 2018, p. 506, grifo nosso).

(EM13LP15) Planejar, produzir, revisar, editar, reescrever e avaliar textos escritos e multissemióticos, considerando sua adequação às condições de produção do texto, no que diz respeito ao lugar social a ser assumido e à imagem que se pretende passar a respeito de si mesmo, ao leitor pretendido, ao veículo e mídia em que o texto ou produção cultural vai circular, ao contexto imediato e sócio-histórico mais geral, ao gênero textual em questão e suas regularidades, à variedade linguística apropriada a esse contexto e ao uso do conhecimento dos aspectos notacionais (ortografia padrão, pontuação adequada, mecanismos de concordância nominal e verbal, regência verbal etc.), sempre que o contexto o exigir. (BRASIL, 2018, p. 509, grifo nosso).

No entanto, ao tratar especificamente do "Campo artístico-literário", deixa-se 
de lado a nomenclatura que vinha sido utilizada e aparece, com maior recorrência, a expressão "gêneros literários":

Estabelecer seleções em perspectivas comparativas e dialógicas, que considerem diferentes gêneros literários, culturas e temas. (BRASIL, 2018, p. 524, grifo nosso).

Encontrar outros tempos e espaços para contemplar a escrita literária, considerando ferramentas e ambientes digitais, além de outros formatos - oficinas de criação, laboratórios ou projetos de escritas literárias, comunidades de escritores etc. Trata-se de lidar com um fazer poético que, conforme já foi explicado, é uma forma de produção lenta e que demanda seleções de conteúdo e de recursos linguísticos variados. [... Esse processo pode até mesmo envolver a quebra intencional de algumas das características estáveis dos gêneros, a hibridização de gêneros ou o uso de recursos literários em textos ligados a outros campos, como forma de provocar efeitos de sentidos diversos na escrita de textos pertencentes aos mais diferentes gêneros discursivos, não apenas os da esfera literária. (BRASIL, 2018, p. 524, grifos nossos).

Principalmente em relação ao último trecho, torna-se mais evidente a distinção entre dois níveis de conceituação: um mais amplo, o dos gêneros discursivos, que englobaria todas as manifestações discursivas/textuais encontradas socialmente, e um mais específico, que diz respeito, estritamente, à esfera literária. No entanto, o documento, ao utilizar tais nomenclaturas, não delimita ou explicita o que se entende em relação a esses conceitos, deixando-nos com algumas dúvidas conceituais.
Vale ressaltar que não há, em nenhum momento, referência à clássica tripartição entre épico, lírico e dramático, o que pode ser justificado pelo fato de a BNCC não se propor a apresentar "conteúdos" a serem ensinados, mas competências e habilidades necessárias para a área e para cada componente. Além disso, é possível pensar que a justificativa para essa ausência esteja, justamente, na percepção de que o esquema tripartido é ultrapassado, ou que os gêneros ditos literários possam significar gêneros textuais de interesse literário, por exemplo. Especificamente quanto à poesia, a falta de referência faz-se ainda mais presente, pois são poucos os momentos em que, referindo-se ao ensino médio, são abordadas questões que se relacionam, direta ou indiretamente, à lírica. Entretanto, há, em uma habilidade específica do campo artístico-literário, a habilidade EM13LP49, uma alusão explícita ao "gênero lírico" (mesmo que não denominado) e a sua caracterização:

Perceber as peculiaridades estruturais e estilísticas de diferentes gêneros literários (a apreensão pessoal do cotidiano nas crônicas, a manifestação livre e subjetiva do eu lírico diante do mundo dos poemas, a múltipla perspectiva da vida humana e social dos romances, a dimensão política e social de textos da literatura marginal e da periferia etc.) para experimentar os diferentes ângulos de apreensão do indivíduo e do mundo pela literatura. (BRASIL, 2018, p. 525, grifos nossos). 
Assim, a partir da redação dessa habilidade, entramos em uma discussão muito mais interna em relação a um gênero literário específico que, tradicionalmente, passou a ser designado como lírico, mas que poderíamos chamar, de modo geral, modernamente, de poesia. Entendendo que o imaginário conceitual do fenômeno lírico apresentado na BNCC dialoga com os apresentados nos livros didáticos aqui abordados, conforme será desenvolvido ao longo deste texto, ressaltamos a permanência - complexa - de um discurso que insiste em caracterizar e apresentar a lírica tendo em vista uma visão que é, sobretudo, romântica (conforme GENETTE, 1986, p. 20-21, entre outros), isso porque a coloca em relação direta com o critério de subjetividade. Dessa forma, vale indagar quais seriam as ressonâncias dessa abordagem e, principalmente, quais seriam suas consequências, que se traduziriam na formação - ou não - de leitores literários no ensino médio.

\section{O Programa Nacional do Livro Didático - histórico e configurações ${ }^{2}$}

Entre os estudiosos que se dedicam à história brasileira dos livros didáticos de Língua Portuguesa, é lugar comum a constatação de que, por muito tempo, predominou a escassez de material e de livros didáticos no país ${ }^{3}$. Esse cenário só começou a ser modificado a partir da década de 70 do século XIX, já com a presença de D. Pedro II na vida cultural do Brasil. Segundo Matta (2010), foram de extrema importância para a história da leitura escolar brasileira os anos finais do Império no Brasil, tendo em vista, principalmente, as mudanças que começaram a acontecer com uma reforma do ensino público. É nesse mesmo sentido que Bittencourt (2004) cita a década de 1880 como um divisor de águas na educação.

Entretanto, durante muito tempo, faltaram sistematização e organização pública em relação aos materiais. Temos somente em 1929 o primeiro marco histórico de interesse estatal sobre o livro didático: a criação do Instituto Nacional do Livro (INL), um órgão específico criado pelo Estado para legislar sobre políticas do livro didático nacional, contribuindo para legitimar e auxiliar o aumento de sua produção. Já em 1938, por meio do Decreto-Lei n.․ 1.006, de 30 de dezembro de 1938, cria-se a Comissão Nacional do Livro Didático (CNLD), estabelecendo-se, assim, a primeira política de legislação e controle de produção e circulação do livro didático. Já em 1971, o INL passa a desenvolver o Programa do Livro Didático para o Ensino Fundamental (Plidef), assumindo as atribuições administrativas e de gerenciamento financeiro até então a cargo da Comissão do Livro Técnico e Livro Didático (Colted). 
Outro marco importante é o ano de 1985, quando o Plidef, por meio do Decreto n. 91.542 , de 19 de agosto de 1985 , dá lugar ao Programa Nacional do Livro Didático (PNLD). Com tal programa, surgem algumas mudanças, como a indicação do livro didático pelos professores, a reutilização do livro, a extensão da oferta aos alunos de $1^{\mathrm{a}}$ e $2^{\mathrm{a}}$ séries, e o fim da participação financeira dos estados, passando-se o controle do processo decisório para a Fundação de Assistência ao Estudante (FAE) e garantindo o critério de escolha de livros pelos professores. Em 1996, inicia-se o processo de avaliação pedagógica dos livros inscritos para o PNLD 1997, procedimento aplicado até hoje e aperfeiçoado ao longo dos anos, com adição de pareceres de uma equipe de especialistas sobre os livros inscritos, conforme se pode perceber em acesso aos Guias de Livros Didáticos, disponibilizados pelo Ministério da Educação ${ }^{4}$.

Em 2017, com o Decreto n. ${ }^{\circ}$ 9.099, de 18 de julho, o Programa Nacional do Livro Didático ampliou seu escopo e passou a se chamar Programa Nacional do Livro e do Material Didático, mantendo-se com a mesma sigla já utilizada anteriormente: PNLD. A diferença é que, agora, além dos livros didáticos, o PNLD é destinado a "avaliar e a disponibilizar obras didáticas, pedagógicas e literárias, entre outros materiais de apoio à prática educativa, de forma sistemática, regular e gratuita" (BRASIL, 2017a, p. 7). Por meio de um único programa, as escolas e os estudantes começam a receber o material necessário para sua permanência e formação nas escolas brasileiras.

O processo acima descrito, mesmo com supressões temporais de ações específicas e modificações importantes na configuração do PNLD, mostra-nos que, a partir de 1929, o interesse pelo livro didático possibilitou a criação de um sistema que modificou as escolas públicas brasileiras de maneira inegável. Vale ressaltar que, neste texto, referimo-nos ao PNLD 2018 como o Programa Nacional do Livro Didático, na sua edição de 2018, conforme orientações, documentos e guias disponibilizados no site do Fundo Nacional de Desenvolvimento da Educação (FNDE) $)^{5}$.

Dessa forma, o PNLD 2018, relativo ao ensino médio, direcionou seu atendimento a todos os alunos das escolas públicas brasileiras matriculados nesse nível de ensino. Especificamente em relação aos livros didáticos de Língua Portuguesa selecionados pelo PNLD $2018^{6}$, livros nos quais são apresentados os conteúdos de Literatura referentes ao "gênero lírico" (assunto de nosso interesse), 11 foram os exemplares selecionados: 
Quadro 1 - Lista de livros didáticos de Língua Portuguesa (PNLD 2018)

\begin{tabular}{|l|l|l|l|}
\cline { 2 - 4 } \multicolumn{1}{l|}{} & \multicolumn{1}{|c|}{ Título da coleção } & \multicolumn{1}{|c|}{ Editora } & Edição \\
\hline LD1 & $\begin{array}{l}\text { Língua Portuguesa: } \\
\text { linguagem e interação }\end{array}$ & $\begin{array}{l}\text { Editora } \\
\text { Ática }\end{array}$ & 3. ed. \\
\hline LD3 & $\begin{array}{l}\text { Ser Protagonista: } \\
\text { Língua Portuguesa }\end{array}$ & $\begin{array}{l}\text { Português: trilhas e } \\
\text { tramas }\end{array}$ & 3. ed. \\
\hline LD4 & $\begin{array}{l}\text { Português } \\
\text { contemporâneo: } \\
\text { diálogo, reflexão e uso }\end{array}$ & $\begin{array}{l}\text { Saraiva } \\
\text { Educação }\end{array}$ & 1. ed. \\
\hline LD5 & $\begin{array}{l}\text { Português: língua e } \\
\text { cultura }\end{array}$ & $\begin{array}{l}\text { Base } \\
\text { Editorial }\end{array}$ & 4. ed.7 \\
\hline LD6 & $\begin{array}{l}\text { Veredas da Palavra } \\
\text { Editora }\end{array}$ & $\begin{array}{l}\text { 1. ed. } \\
\text { Ática }\end{array}$ \\
\hline LD7 & Novas Palavras & FTD & 3. ed. \\
\hline LD8 & Esferas das linguagens & FTD & 1. ed. \\
\hline LD9 & $\begin{array}{l}\text { Vivá - Língua } \\
\text { Portuguesa }\end{array}$ & $\begin{array}{l}\text { Editora } \\
\text { Positivo }\end{array}$ & 1. ed. \\
\hline LD10 & $\begin{array}{l}\text { Português: contexto, } \\
\text { interlocução e sentido }\end{array}$ & Moderna & 3. ed. \\
\hline LD11 & $\begin{array}{l}\text { Se liga na língua: } \\
\text { literatura, produção de } \\
\text { texto, linguagem }\end{array}$ & Moderna & 1. ed. \\
\hline Fon & Elabado pelos autores, & com base em Brasi \\
\hline
\end{tabular}

Fonte: Elaborado pelos autores, com base em Brasil (2017b).

Antes de partirmos para a análise e a discussão dos conceitos apresentados nos livros em questão, tecemos, a seguir e brevemente, algumas considerações a respeito da problemática envolvendo a própria conceituação de "gênero lírico". Entretanto, vale pontuar que tal impasse não se restringe somente à definição em si do fenômeno lírico presente nos livros didáticos, mas se relaciona com um processo muito mais complexo de transformação de conceitos teóricos/literários em conceitos didáticos.

\section{"Gênero lírico": impasses de conceituação e escolarização}

O "gênero lírico" é marcado, historicamente, por uma falta de definição que dê conta da sua complexidade e da pluralidade de manifestações poéticas dos outrora chamados "gêneros menores". Porém, além dessas especificidades conceituais, tal definição também passa por dificuldades pelas quais, vale ressaltar, todos os saberes escolarizados também passam. Nesse caminho, estão as considerações de Soares (2004) sobre o processo de escolarização do conhecimento. Ao discutir os problemas de transformação de uma área de conhecimento em disciplina curricular, a autora aponta para os problemas que envolvem esse processo de escolarização, entendido como o estabelecimento de um saber a ser ensinado e aprendido na escola.

Segundo Chevallard (1991), a transposição didática (o que chamamos aqui de "escolarização") é a transformação de um saber científico ou técnico para um saber escolar. Nessa transposição, o saber "teórico" acaba passando por algumas mudanças, como adaptações ao contexto escolar, por exemplo, com o objetivo de torná-lo mais compreensível aos alunos. É isso o que ocorre também com o ensino de literatura, uma vez que o saber teórico difundido pela Teoria da 
Literatura chega às escolas de uma maneira muito mais "palpável" aos alunos, o que é compreensível e, obviamente, necessário. O que se questiona é que essa transposição, muitas vezes, acaba por selecionar e distorcer os saberes construídos, prejudicando a compreensão dos alunos e, mais grave ainda, a formação de leitores literários.

É indiscutível que, no momento de sistematização do saber teórico a respeito do "gênero lírico" (que, diga-se de passagem, é bastante amplo e complexo) em saber escolar, muito se perde e muito se simplifica. Entretanto, essa transformação não pode ser generalista demais a ponto de dificultar e comprometer a leitura de textos literários desse gênero, uma vez que não privilegiaria a formação de leitores literários, uma necessidade e um objetivo já cristalizados das aulas de literatura. Dessa forma, faz-se necessário o estabelecimento de critérios e de objetivos da escolarização desse conhecimento, tendo em vista, sempre, que um conceito teórico desenvolvido e estudado nas escolas de educação básica deve servir de auxílio para a leitura dos textos literários.

Retomando a última citação anteriormente apresentada da BNCC, percebemos que, ao referenciar a manifestação do "eu lírico", a caracterização da poesia encontra-se ancorada em uma suposta relação entre o fazer poético e a subjetividade, o mundo interior do "eu lírico" (ou, muitas vezes, do próprio poeta). Nesse universo, é muito comum, ao discutirmos questões referentes às problemáticas que envolvem a definição de "gênero lírico" (de maneira conceitual e genérica), depararmo-nos com outra discussão bastante controversa no mundo acadêmico: a que diz respeito à subjetividade. Isso porque a subjetividade é, frequentemente, considerada como uma característica definidora desse gênero, em contraste com os dois outros gêneros literários pertencentes à tríade tradicionalmente apresentada aos alunos: o épico e o dramático. Além disso, entram nessas discussões as leituras e as análises anacrônicas dos mais diversos textos literários produzidos até então, o que contribui, consequentemente, para uma abordagem teoricamente discutível da poesia, para não se mencionar demais fatores de ordem mais pragmática.

De acordo com Genette (1986) e Berrio (2015), esse olhar para o "gênero lírico" é fruto, sobretudo, dos pressupostos teóricos românticos frente aos gêneros literários, principalmente a partir das teorizações de G. W. F. Hegel. Para compreender essa configuração, precisamos retomar, brevemente, os textos fundadores da sistematização que envolve os gêneros literários: A República, de Platão, e, principalmente, a Poética, de Aristóteles.

Em seu mais longo diálogo, composto por 10 livros, Platão apresenta uma pro- 
posta de cidade ideal e de seu funcionamento. Bastante conhecida é a afirmação de que, na obra, o filósofo grego propõe a expulsão dos poetas de sua cidade ideal. Porém, vale lembrar que a poesia que é relegada à exclusão é a considerada "subversiva", não a poesia "didática", que ensinaria bons valores aos homens. No segundo livro da obra, encontramos uma referência inicial à origem da discussão dos três gêneros. Entretanto, temos um problema que é, sobretudo, tradutório ${ }^{8}$, pois, costumeiramente, em vez de citar "poesia épica, mélica [melos] e dramática", registra-se "poesia épica, lírica e dramática", para referenciar as três formas de apresentação: recitação, canto e apresentação, como ensina o crítico canadense Northrop Frye (2013). Dessa forma, encontramos nessa passagem uma das origens da problemática conceituação de "lírica" nos estudos literários, como um de três gêneros literários.

Além disso, é também um equívoco bastante disseminado, inclusive nos livros didáticos selecionados no PNLD 2018, a afirmação de que foi Aristóteles que distinguiu três gêneros literários: 0 épico, o lírico e o dramático. Para delimitar seu objeto de estudo, Aristóteles, por meio de sua constatação de que todas as manifestações artísticas são imitação, distingue a "poesia" a partir de três critérios: os meios, os objetos e os modos. Quanto a este último, teorizado no terceiro capítulo de Poética, Aristóteles identi- fica dois modos principais de imitação: a narrativa e a mímese (drama), na esteira do que Platão definira em A República ${ }^{9}$. $O$ primeiro modo subdivide-se em dois: a narrativa pura (que tem como exemplo o ditirambo) e a narrativa mista (cujo exemplo são as epopeias homéricas).

Como se pode perceber, a sistematização empreendida por Aristóteles restringe-se aos modos de apresentação da poesia, não aos conceitos de "gêneros literários" aos quais nos referimos atualmente. Ademais, o exemplo de narrativa pura a que o grego se refere é o ditirambo ${ }^{10}$, uma manifestação com a qual não temos contato, pois não chegou até nós nenhum exemplo concreto desse tipo de produção. Dessa forma, associar a narrativa pura, ou seja, o ditirambo, ao conceito de "gênero lírico", não encontra respaldo teórico nos pressupostos aristotélicos. Faz-se necessária, então, uma desmitificação da premissa dos três gêneros em Platão e, principalmente, em Aristóteles, uma ideia já consolidada e tradicionalmente escolarizada nos livros didáticos.

Nesse caminho, Berrio (2015), ao construir uma revisão teórica e histórica do problema de conceituação dos gêneros literários, afirma que a concepção atual referente aos gêneros literários é fruto das ideias estabelecidas em duas grandes épocas da teoria literária: o Classicismo e o Romantismo. De maneira geral, para ele, os teóricos 
classicistas foram os responsáveis por promover a junção entre os três modos de apresentação dos textos apresentados por Platão e Aristóteles à tradicional tripartição dos gêneros literários em épico, lírico e dramático. Na sequência, foram os românticos, principalmente na figura central de Hegel, que propiciaram a união dessa já consolidada tripartição a uma teoria evolucionista ligada à objetividade e à subjetividade: enquanto a épica é objetiva, a lírica é subjetiva, e o drama é a síntese entre a objetividade e a subjetividade ${ }^{11}$. É essa associação da lírica à subjetividade que encontramos até hoje nos principais livros didáticos que apresentam os gêneros literários (assim como no trecho da BNCC transcrito anteriormente).

Como se pode depreender, essa mitificação envolvendo os gêneros literários apresentada pelos manuais didáticos tende a refletir no modo de olhar os textos poéticos por parte dos alunos. Nossa problematização principal encontra-se na discussão a respeito dos critérios utilizados para a apresentação dessa teoria, uma vez que, como observaremos nos livros, não há um direcionamento teórico frente à leitura dos poemas. Além dos problemas conceituais envolvendo o "gênero lírico", a teoria apresentada pelo livro didático, além de não dar conta das diferentes manifestações literárias com as quais o aluno irá se deparar, como é o caso, sobretudo, da literatura moderna e contemporânea, não auxilia o próprio ato da leitura do texto literário, pois os pressupostos teóricos apresentados não se confirmam no contato com muitos poemas.

\section{PNLD 2018: análise e discussão dos livros didáticos selecionados}

Como escolha metodológica, realizamos, em primeiro lugar, uma leitura global das abordagens do "universo lírico" nos livros didáticos. Por "universo lírico", entendemos todos os tópicos que, de uma maneira ou de outra, apresentam, discutem e analisam poemas líricos. Entretanto, para delimitar e sistematizar nossa análise, detivemo-nos em um aspecto específico: a definição de "gênero lírico”. No Quadro 2, é possível verificar um recorte das definições apresentadas por cada um dos livros analisados: 


\begin{tabular}{|c|c|}
\hline & \\
\hline LD1 & $\begin{array}{l}\text { "[...] textos em que um eu lírico expõe sentimentos e emoções. O eu poético concentra-se em sua } \\
\text { realidade interior, em seus sentimentos, e procura expressá-los em verso, na forma de poemas. } \\
\text { Descrições e narrações, quando ocorrem nesse gênero, funcionam como pretexto para o eu lírico } \\
\text { falar de si mesmo." (FARACO; MOURA; MARUXO JÚNIOR, 2016, p. 47). }\end{array}$ \\
\hline LD2 & $\begin{array}{l}\text { "[...] texto em que o 'eu' vivencia e manifesta emoções; construção que explora o universo íntimo do } \\
\text { ser humano. A subjetividade é sua característica marcante. Define-se pela expressão em primeira } \\
\text { pessoa do singular localizada no presente." (BARRETO; BÁRBARA; BERGAMIN, 2016, p. 50). } \\
\text { "A poesia lírica, desde sua origem na Grécia Antiga, apresenta aspectos da subjetividade de um } \\
\text { 'eu' - seus comportamentos, pensamentos, sentimentos e vivências interiores. [...] No poema lírico } \\
\text { há sempre um 'eu' que se expressa. É em torno desse eu que todo o poema se constrói. [...] na po- } \\
\text { esia lírica, está em jogo a subjetividade do eu para além das experiências vivenciadas pelo autor." } \\
\text { (BARRETO; BÁRBARA; BERGAMIN, 2016, p. } 51 \text { ). }\end{array}$ \\
\hline LD3 & Não apresenta conceituação sobre "gênero lírico". (SILVA; SETTE; TRAVALHA; BARROS, 2016). \\
\hline LD4 & $\begin{array}{l}\text { "Nas composições do gênero lírico, não há personagens e o poeta se expressa na voz de um eu } \\
\text { lírico que fala de suas emoções e impressões sobre o mundo. Em geral, essas composições explo- } \\
\text { ram efeitos sonoros, tais como repetição, ritmo e a musicalidade das palavras." (CEREJA; VIANNA; } \\
\text { DAMIEN, 2016, p. 32). }\end{array}$ \\
\hline LD5 & Não apresenta conceituação sobre "gênero lírico". (FARACO, 2013). \\
\hline LD6 & $\begin{array}{l}\text { "[...] tem como objeto o mundo interior do poeta, sendo, portanto, mais subjetivo que o gênero épi- } \\
\text { co. Nele, uma voz central exprime suas emoções e reflexões, expressando-se por meio de poemas } \\
\text { que, na época de Aristóteles, eram relativamente curtos e caracterizavam-se mais pela exploração } \\
\text { de sentimentos do que pela narração de acontecimentos, o que era próprio da poesia épica." (AL- } \\
\text { VES; MARTIN, 2016, p. 19). }\end{array}$ \\
\hline LD7 & $\begin{array}{l}\text { ra lírica, um sujeito que chamamos eu lírico, sujeito lírico, voz lírica ou voz poética exprime } \\
\text { moções. [...] É, dos três gêneros literários, o mais subjetivo. } \\
\text { erísticas do gênero lírico: } \\
\text { tivo por excelência; - expressão do mundo interior (espaços, coisas, pessoas do mundo } \\
\text { o são evocações) de um eu (sujeito lírico); - tempo: preponderância do presente; - sem pro- } \\
\text { o temporal." (AMARAL; FERREIRA; LEITE; ANTÔNIO, 2016, p. 57). }\end{array}$ \\
\hline LD8 & $\begin{array}{l}\text { "Características do gênero lírico: } \\
\text { - O autor cria um eu poético que representa suas relações com seu mundo interior, revelando emo- } \\
\text { ções e sentimentos de amor, raiva e ódio por meio das palavras, das imagens e do ritmo recriado. } \\
\text { - O assunto predominante é a expressão de sentimentos e de emoções, impressões subjetivas." } \\
\text { (CAMPOS; ASSUMPÇÃO, 2016, p. 72). }\end{array}$ \\
\hline LD9 & $\begin{array}{l}\text { "[...] expressão dos sentimentos e das emoções do eu lírico. A poes } \\
\text { tos e aventuras como os poemas épicos. Exprime o mundo interio } \\
\text { de um poema de denúncia social, por exemplo, o que se expressa } \\
\text { problema, e não os fatos objetivos." (CAMPOS; MARQUES; ANDF }\end{array}$ \\
\hline LD10 & $\begin{array}{l}\text { "A poesia lírica surge como uma forma de atender a esse anseio [de expressão individual e subje- } \\
\text { tiva]. Ela se define pela expressão de sentimentos e emoções pessoais. } \\
\text { O gênero lírico define-se, portanto, como aquele em que uma voz particular - o eu lírico (ou eu poe- } \\
\text { mático) - manifesta a expressão do mundo interior, ou seja, fala de sentimentos, emoções e estados } \\
\text { de espírito." (ABAURRE; ABAURRE; PONTARA, 2016, p. 29). }\end{array}$ \\
\hline LD11 & $\begin{array}{l}\text { "[...] em que o poeta faz uso de um eu poemático para expressar subjetivamente seu mundo inte- } \\
\text { rior." (ORMUNDO; SINISCALCHI, 2016, p. 28). } \\
\text { "Gênero lírico: expressão do 'eu' } \\
\text { O poeta expressa seu mundo interior (sua subjetividade) falando em primeira pessoa, por meio de } \\
\text { um 'eu'. } \\
\text { O gênero lírico é uma categoria de textos literários em que o 'eu' parte de seu mundo interior para } \\
\text { expressar sentimentos de toda natureza (amor, dor, ódio, horror, saudade, etc.)." (ORMUNDO; } \\
\text { SINISCALCHI, 2016, p. 34). }\end{array}$ \\
\hline
\end{tabular}

Fonte: Elaborado pelos autores. 
Dos 11 livros didáticos analisados, 9 deles apresentam definições e características específicas para o "gênero lírico". Com o objetivo de organizar nossas análises, dividimos os materiais em duas etapas principais: a dos livros que apresentam as conceituações (9 deles) e a dos livros que apresentam outra forma de organização didática e metodológica, sem apresentar conceituação específica sobre o "gênero lírico" (2 deles: LD3 e LD5). Com isso, nosso objetivo é também perceber qual das duas abordagens auxilia de maneira mais orientada a leitura de poesia por parte dos alunos.

Iniciando pela análise dos conceitos apresentados, é perceptível a ênfase centrada no caráter subjetivo que caracterizaria o gênero: dos 9 livros analisados, todos eles apresentam referências explícitas ao "mundo interior" e à expressão de "emoções" e "sentimentos" de um "eu". Isso quer dizer que, quando são apresentadas definições desse gênero em livros didáticos, há um percentual de $100 \%$ de referência à associação do gênero lírico com o critério de subjetividade. Retomando Berrio (2015), portanto, podemos perceber que os 9 livros didáticos enquadram-se na tradição de conceituação da lírica que é fruto das leituras classicistas e, principalmente, românticas frente o fenômeno lírico e as teorizações anteriores.

Além disso, alguns livros, como o LD2 e o LD6, fazem referência ao universo grego antigo como forma de complementar e exemplificar as informações apresentadas. Como afirma Miller (1994), a definição moderna de lírica (fruto de uma leitura romântica, como vimos) não pode ser parâmetro para se pensar a produção antiga, pois, segundo o autor, a lírica, conforme pensada modernamente, não inicia na Grécia antiga nem com os poetas do período helenístico ( 3 a. C. -1 a.C.), mas somente no período romano (1 a. C - 4 d. C.). Ademais, o autor afirma que o imaginário de um poema de revelação pessoal, que projeta a imagem de uma consciência individual e subjetiva, só é possível na cultura escrita, o que não condiz com os poemas orais das épocas mais antigas citadas como exemplos ${ }^{12}$.

Uma de nossas perguntas, nesse caminho, é: como a delimitação da poesia lírica de forma restrita e associada à subjetividade pode contribuir para o contato dos alunos com as mais diversas produções líricas (tendo em vista a ampla seleção temporal de textos escolhidos para leitura nos livros didáticos)? Resta-nos analisar, então, como os livros didáticos que não apresentam tais definições desenvolvem a organização e a abordagem didática do "universo lírico".

No LD3, o sumário do livro conta com uma organização em 4 tópicos principais: linguagem (de modo mais amplo), literatura, gramática e produção de textos. Na seção destinada à literatura, inicia-se com uma visão geral sobre o que é lite- 
ratura (texto literário e não literário) e, na sequência, são propostas leituras de textos literários que ou seguem um padrão temático (por exemplo, capítulo 11: "Literatura e o cenário urbano") ou um padrão temporal (por exemplo, capítulo 15: "Poéticas brasileiras da segunda metade do século XX ao século XXI").

Tomando como exemplo o capítulo 15 , acima denominado, devido ao fato de propor leituras de poemas ao longo de todas as suas páginas, é importante observar que, ao apresentar cada texto literário, apresenta-se também uma breve contextualização sobre o autor (poeta) e sobre a época em que foi escrito (em uma espécie de "periodização" da produção literária). No entanto, essas apresentações sobre autores e épocas são feitas a partir da leitura dos poemas, não como simples conteúdos lineares e informações soltas no decorrer do capítulo. Além disso, vale ressaltar que as questões a partir da leitura dos poemas concentram-se, em sua maioria, em auxiliar a compreensão dos textos, como perguntas que atentam para a disposição gráfica das palavras, para os aspectos semânticos das escolhas linguísticas, para as finalidades comunicativas dos poemas, etc.

Já em relação ao LD5, surpreende, à primeira vista, os critérios escolhidos para organização do sumário: os 5 capítulos iniciais são denominados de acordo com gêneros: crônica, conto e romance. Os capítulos 6 a 10 são denominados apenas como "Literatura", sendo subdivididos de acordo com os períodos da história da literatura brasileira. Na sequência, os capítulos 10 a 13 denominam-se "Enciclopédia da linguagem", enquanto os capítulos 14 e 15 são intitulados de "Almanaque gramatical”. Além disso, o livro ainda conta com 3 apêndices que se dedicam a questões mais gramaticais, como pontuação, acentuação e uso de hífen.

Ao analisar os poemas propostos para leitura e as reflexões e questões proporcionadas a partir deles, é possível perceber que os comentários a respeito de caracterização de eu lírico, de características temáticas dos poemas e de aspectos contextuais são abordadas a partir de cada poema em específico, não apresentando sistematizações mais globais a respeito do fenômeno poético de maneira geral. Nesse sentido, pode-se depreender que as discussões propostas partem de cada texto literário particular, levando-se em conta muito mais a própria leitura do texto e o que ela pode suscitar em termos interpretativos do que "conteúdos" pré-definidos e pré-delimitados. No entanto, é evidente que, principalmente, o critério temporal foi utilizado para a seleção e a ordenação de apresentação dos textos, visto ser necessária uma delimitação e uma escolha para ela.

Nesse sentido, levando em consideração o apresentado em seção anterior deste artigo e as análises realizadas, po- 
demos afirmar que, quando existem, as definições de "gênero lírico" são baseadas na concepção romântica de poesia, que relaciona o gênero às características de expressão da subjetividade, do mundo interior, do "eu" do poeta. Assim, fora dessa configuração, identificamos uma certa simplificação do fenômeno lírico, pois as definições apresentadas ignoram as nuances e as especificidades históricas e contextuais de cada texto literário, em uma tentativa de conceituação globalizante que dê conta de definir e de caracterizar o "gênero lírico" de maneira geral.

\section{Uma proposta de conclusão: caminhos e possibilidades}

Acreditamos que simplificar a conceituação de "gênero lírico", como se tem feito atualmente, conforme exemplificaram as análises dos livros didáticos aqui desenvolvidas, é muito mais problemático do que simplesmente apresentá-la como uma conceituação complexa e passível de exceções, que leve em conta as particularidades de cada período e a contextualização histórica. A necessidade de generalização, nesse caso e em muitos outros, somente contribui para uma leitura errônea do fenômeno literário produzido ao longo do tempo. Não seria melhor ensinar a ler os diferentes textos literários de acordo com suas especificidades em vez de seguir na tentativa de generalização e simplificação de conceitos que, como se sabe, não são gerais nem simples? Isso não quer dizer abrir mão de uma tentativa de explicação conceitual, mas sim dar espaço para a reflexão e para a compreensão das características históricas e culturais do conceito de "gênero lírico", levando-se em consideração as diversas manifestações literárias com as quais tivemos, temos e teremos contato.

Além disso, é importante retornarmos à BNCC e ao seu aspecto norteador mas não opressor - em relação à organização curricular. Com a nova proposta por áreas e com o caráter mais "aberto" do ensino médio, é possível aproveitar essa liberdade para distanciarmo-nos dos moldes padrões e estáticos de abordagem da literatura e partirmos para uma proposta mais ampla e que envolva, acima de tudo, a formação de leitores literários:

Diferentemente do Ensino Fundamental, para o Ensino Médio não há indicação de anos na apresentação das habilidades, não só em função da natureza mais flexivel do currículo para esse nível de ensino, mas também, como já referido, do maior grau de autonomia dos estudantes, que se supõe alcançado. Essa proposta não mais impõe restrições e necessidades de estabelecimento de sequências (que já são flexíveis no Ensino Fundamental), podendo cada rede de ensino e escola definir localmente as sequências e simultaneidades, considerados os critérios gerais de organização apresentados em cada campo de atuação. (BRASIL, 2018, p. 501, grifos nossos). 
Nesse sentido, pensamos que a didatização da poesia precisa objetivar, em primeiro lugar, uma proposta de aproximação do leitor com os textos literários. Assim, as escolhas teóricas e metodológicas precisam contribuir para essa aproximação, possibilitando que os alunos, ao longo de suas leituras, familiarizem-se cada vez mais com a compreensão e com as particularidades do fenômeno poético. No entanto, é evidente que se fazem necessárias algumas escolhas em relação à seleção de textos e à ordenação dos materiais a serem trabalhados. Além disso, precisa-se definir com que objetivo cada texto será lido e o que será explorado dessa leitura, tendo-se em vista que eles também contribuem para uma construção de repertório cultural e linguístico de cada aluno.

Como decisão inicial, acreditamos que, atualmente, precisamos partir do mundo do aluno para construir pontes até um mundo desconhecido, de forma a aproximá-lo e a provocá-lo para a leitura dos textos. Nesse caminho, o aluno não pode chegar ao primeiro contato com o texto sem bagagem alguma: o professor tem papel fundamental nesse processo para muni-lo das informações ou das motivações necessárias para essa primeira aproximação. De acordo com Rouxel (2013, p. 27), “a inventividade do professor é requisitada para elaborar um dispositivo capaz de interpelar os alunos", ou seja, ele é o mediador encar- regado de construir a ponte que deve ser estabelecida entre o mundo conhecido do aluno e o mundo desconhecido do poema a ser lido.

Assim, nossa proposta encontra-se ancorada na ideia de movimento contínuo de literatura, apresentada por Cosson (2018), que é justamente a de partir do universo conhecido do aluno para o desconhecido. Para tanto, faz-se necessária a construção de uma "ponte" entre esses dois universos, o que precisa ser realizado antes do contato do aluno com o texto propriamente dito. Pensamos que uma forma de alcançar essa ponte é organizar um planejamento didático pautado em temas recorrentes presentes nas mais diversas manifestações literárias, o que não é nenhuma novidade em termos de perspectivas de organização metodológica do ensino da literatura. Porém, acreditamos que a organização temática, além de organizar e aproximar os textos a serem lidos (de diferentes autores, nacionalidades e épocas), precisa aproximar o aluno a esse universo.

De maneira mais direta, propomos que a leitura de uma coletânea de textos temáticos (dos mais diferentes gêneros) precisa estar precedida de uma motivação para essa leitura. Dessa forma, se o tema a ser topicalizado é o "amor", por exemplo, precisam ser discutidas questões relacionadas ao assunto previamente, e, preferencialmente, precisam ser lidos diferentes textos que se refiram ao 
tema. Esses textos iniciais devem fazer parte do cotidiano dos alunos, como todas as novas configurações textuais que surgiram a partir das novas tecnologias e do uso da internet por parte dos jovens. Ao perceberem que os textos lidos e o assunto central fazem parte de seu mundo conhecido ${ }^{13}$, eles estarão mais bem preparados para uma primeira aproximação com o texto literário, que tende a ser, por sua própria configuração, de maior complexidade linguística.

Além disso, a proposta de diversidade de textos também visa a possibilitar um olhar mais amplo ao aluno, que poderá passar a perceber como a temática do amor, por exemplo, foi importante desde as primeiras manifestações literárias até as mais recentes, afetando histórias e povos passados. Involuntariamente, o próprio aluno poderá perceber um viés histórico entre os textos, ao refletir sobre as diferentes concepções e abordagens direcionadas ao tema e que estão expressas nas mais diversas materializações literárias. Por meio desse caminho, o aluno poderá estabelecer comparações entre os valores e os discursos de cada período histórico e de cada ambiente cultural, possibilitando que reconheça as especificidades de cada período literário e seu caráter social, indo ao encontro do proposto na Competência Específica 6 da BNCC:
Apreciar esteticamente as mais diversas produções artísticas e culturais, considerando suas características locais, regionais e globais, e mobilizar seus conhecimentos sobre as linguagens artísticas para dar significado e (re)construir produções autorais individuais e coletivas, exercendo protagonismo de maneira crítica e criativa, com respeito à diversidade de saberes, identidades e culturas. (BRASIL, 2018, p. 496).

Para complementar e auxiliar essa leitura, o professor precisará, novamente, figurar como um mediador entre o aluno e o texto a ser lido. Nesse momento, ele precisa utilizar as ferramentas da Teoria da Literatura para facilitar a aproximação entre os dois mundos: como as questões propostas após a leitura dos poemas podem auxiliar na compreensão do texto? Aqui, vale observar que cada texto demandará questões específicas de atenção ao uso e à expressividade da linguagem, mas que parecerão, aos olhos do aluno, muito mais naturais, pois é a própria leitura que passa a exigir tais questionamentos.

Desse modo, não se estaria mais partindo dos "conteúdos" sobre conceito de eu lírico, figuras de linguagem, metrificação, por exemplo, e utilizando os poemas (ou trechos deles, muitas vezes) somente como exemplificação dessa teorização. Os alunos poderiam perceber tais especificidades no próprio funcionamento na linguagem, conseguindo atribuir uma significação a tais con- 
ceitos. Ao final de um longo trabalho de leitura e compreensão desses poemas, os próprios alunos conseguirão, por meio de comparações com outros textos literários lidos, perceber o que se distancia e o que se aproxima entre os diferentes gêneros e expressões literárias. Fica evidente, portanto, que, no caso da poesia, muitas dessas leituras poderão não encetar nenhuma abordagem que implique $o$ conceito de "subjetividade", que, a julgar pelas definições dos livros didáticos, seria central para esse(s) gênero(s).

Sendo assim, acreditamos que mais vale um aluno que saiba ler e que se sinta à vontade para ler um poema do que um aluno que simplesmente decora conceitos e sistematizações que, muitas vezes, nem se comprovam no próprio ato da leitura e não auxiliam a compreensão (e interpretação) da materialidade a ser lida. Insiste-se, então, na importância de a ponte entre o aluno e o texto partir de seu mundo conhecido, cotidiano, confortável, para se chegar aos diferentes mundos aos quais a leitura literária especialmente a de poesia - pode nos transportar.

\section{Definitions of 'Lyric Genre' in Textbooks: questions and possibilities regarding readers' education}

\section{Abstract}

This article aims at presenting a survey of concepts of the lyric genre' present in Portuguese language textbooks selected by the 2018 edition of the National Program for Textbooks (PNLD). Stemming from the difficulties concerning the approach to reading poems in classroom, one of the objectives of this article is to verify in what measure the problematic conceptualization of lyric interferes - rather negatively - in the proper reading of literary texts in classroom by presenting theoretical concepts that are not rooted in the very act of reading the selected texts. Hence, by recovering the schooling of poetry and realizing which features contribute for the permanence of its troubling teaching, this article proposes, in a synthetic way, a possibility of a didactic approach that aims at appeasing the difficulties concerning the literary education of readers of poetry in schools.

Keywords: Poetry schooling; lyric genre; reading; textbooks

\section{Notas}

1 Optamos por utilizar "gênero lírico" entre aspas devido à problematização referente à definição do conceito. No decorrer deste artigo, tal conceituação será discutida de forma mais detalhada.

2 As informações históricas da trajetória das políticas sobre livros didáticos apresentadas neste tópico foram retiradas de BROLEZZI, Antônio Carlos. Histórico do PNLD, 2008. Disponível 
em: <https://www.ime.usp.br/ brolezzi/disciplinas/20082/mat0412/textos/historiadopnld. doc>. Acesso em: 20 mar. 2019.

3 Exemplos de trabalhos que seguem essa afirmação são Batista, Galvão e Klinke (2002), Matta (2010) e Bittencourt (2004).

4 Para acesso aos Guias, consultar: http://www. fnde.gov.br/programas/programas-do-livro/ pnld/guia-do-livro-didatico?limitstart=0. Acesso em: 4 abr. 2019.

5 Todas as informações referentes ao PNLD 2018 podem ser encontradas por meio do link: https://www.fnde.gov.br/index.php/programas/ programas-do-livro/pnld/guia-do-livro-didatico/ item/11148-guia-pnld-2018.

6 Para download do Guia de Língua Portuguesa, consultar: http://www.fnde.gov.br/programas/ programas-do-livro/pnld/guia-do-livro-didatico/ item/11148-guia-pnld-2018. Acesso em: 4 abr. 2019.

7 Não tivemos acesso à edição selecionada no PNLD 2018. Entretanto, utilizamos para a análise a $3^{\underline{a}}$ edição do livro, de 2013.

8 Como exemplos, cita-se a tradução utilizada neste texto, de Maria Helena da Rocha Pereira: "[...] quer se trate de poesia épica, lírica ou trágica." (PLATÃO, 2001, p. 90), bem como a tradução de Carlos Alberto Nunes: “[...] pouco importando o gênero de poesia em que apareça: épico, lírico ou trágico" (PLATÃO, 2000, p. 125).

9 No "Livro III" de A República, Platão apresenta três tipos de narrativa: uma que é totalmente imitativa (a mímese - imitação); uma que é totalmente não imitativa (a narrativa simples); e uma que mistura essas duas formas (a narrativa mista). Assim, na mímese, só as personagens falam, não havendo interferência do poeta (a exemplo da tragédia e da comédia); na narrativa simples, somente o poeta fala; na narrativa mista, por fim, o poeta fala em seu próprio nome e também como personagem (a exemplo da epopeia). Entende-se, portanto, como a tradição aproximou a narrativa simples da lírica e, esta, posteriormente, como apresentando a voz do próprio poeta.

10 Segundo Genette (1986, p. 24-25), o ditirambo é hoje uma forma mal conhecida, da qual não temos exemplos, mas que, no geral, é descrita "como um 'canto coral em honra de Dionísio', e que se inclui, pois, sem outros impedimentos entre as 'formas líricas"'. Na sequência, o autor ainda afirma que não há, nos textos de Aristóteles e Platão, nada que autorize apresentar o ditirambo como ilustrando o "gênero lírico".
11 É bom notar que esse esquema apresenta diversos arranjos diferentes, conforme o autor, apesar de este ser o mais comum. Para uma visão sintética do assunto, ver Kayser (1976).

12 A questão da lírica anterior à modernidade é um tópico controverso, especialmente por não ter havido, contrariamente à tragédia, à comédia e à epopeia, definições antigas acerca do assunto, como bem explica Genette (1986), fato esse decorrente, em parte, por não haver um único gênero que desse conta daquilo que Platão chamou de "poesia mélica", mas vários, e, em parte, por não haver uma teorização acerca dos gêneros temáticos, que foram, por muito tempo, considerados não miméticos. A teoria de Miller (1994), nesse sentido, é interessante, apesar de não ser uma unanimidade dentre os estudiosos da poesia antiga, pois o crítico americano busca se distanciar da tradição que identificava o surgimento da lírica na Grécia antiga como decorrente de um processo de individualização, ocorrido a partir do século VI a. C, resultante da vida na pólis. Essa tradição, que possui em Jaeger (1994) e Snell (2001) seus maiores expoentes, é ainda muito influente nesse campo, justamente por partir das mesmas premissas teóricas de raiz hegeliana.

13 Com as diversas e aceleradas transformações pelas quais passamos atualmente, que dizem respeito, principalmente, às relações sociais no mudo moderno, convém refletir sobre o "novo" papel da escola nesse contexto. Insere-se, no ambiente escolar, o desafio de trabalhar com as novas tecnologias e com as diferentes "bagagens" trazidas pelos alunos, tendo em vista que, muitos deles (e cada vez mais) são nativos digitais e estão em contato diário com inúmeras manifestações linguísticas e literárias. Nesse caminho, na mesma esteira de pensamento de Moran (1997) e Maraschin (2000), acreditamos que a escola não apresenta mais o papel de transmitir a informação, pois ela já está dada em outros contextos, mas o de auxiliar o aluno no contato com essas informações, habilitando-o para um posicionamento mais seletivo, crítico e reflexivo em relação ao que se lê diariamente. 


\section{Referências}

ABAURRE, Maria Luiza M.; ABAURRE, Maria Bernadete M.; PONTARA, Marcela. Português: contexto, interlocução e sentido. Vol. 1. 3. ed. São Paulo: Moderna, 2016.

ALVES, Roberta Hernandes; MARTIN, Vima Lia. Veredas da palavra. Vol. 1 São Paulo: Ática, 2016.

AMARAL, Emília; FERREIRA, Mauro; LEITE, Ricardo; ANTÔNIO, Severino. Novas palavras. Vol. 1. 3. ed. São Paulo: FTD, 2016.

ARISTÓTELES. A poética clássica. Tradução de Jaime Bruna. São Paulo: Cultrix, 2014.

BARRETO, Ricardo Gonçalves; BÁRBARA, Marianka Gonçalves-Santa; BERGAMIN, Cecília. Ser protagonista: língua portuguesa. Vol. 1. 3. ed. São Paulo: Edições SM, 2016.

BATISTA, Antônio Augusto Gomes; GALVÃO, Ana Maria de Oliveira; KLINKE, Karina. Livros escolares de leitura: uma morfologia (1866-1956). Revista Brasileira de Educação, Rio de Janeiro, n. 20, p. 27-47, mai./ago. 2002.

BERRIO, Antonio García; CALVO, Javier Huerta. Los géneros literarios: sistema e historia. 6. ed. Madrid: Cátedra, 2015.

BITTENCOURT, Circe Maria Fernandes. Autores e editores de compêndios de leitura (1810-1910). Educação e Pesquisa, v. 30, n. 3. São Paulo: USP, set./dez. 2004.

BRASIL. Ministério da Educação. Base Nacional Comum Curricular. Brasília, 2018.Disponível em: <http://basenacionalcomum.mec. gov.br/images/BNCC_EI_EF_110518_versaofinal_site.pdf>. Acesso em: 23 abr. 2019.

BRASIL. Ministério da Educação. Decreto $n$. 9.099, de 18 de julho de 2017. Diário Oficial [da] União, Seção 1, Página 7, 19 jul. 2017a. Disponível em: <https://www2.camara.leg. br/legin/fed/decret/2017/decreto-9099-18-julho-2017-785224-publicacaooriginal-153392-pe.html>. Acesso em: 17 out. 2019.
BRASIL. Ministério da Educação. PNLD 2018: língua portuguesa - guia de livros didáticos - Ensino Médio. Ministério da Educação - Secretária de Educação Básica SEB - Fundo Nacional de Desenvolvimento da Educação. Brasília, DF: Ministério da Educação, Secretária de Educação Básica, 2017b.

BROLEZZI, Antônio Carlos. Histórico do PNLD, 2009. Disponível em: <https://www. ime.usp.br/ brolezzi/disciplinas/20082/ mat0412/textos/historiadopnld.doc.>. Acesso em: 20 mar. 2019.

CAMPOS, Elizabeth; MARQUES, Paula; ANDRADE, Silvia. Vivá: língua portuguesa. Vol. 1. Curitiba: Positivo, 2016.

CAMPOS, Maria Inês Batista; ASSUMPÇÃO, Nivia. Esferas da linguagem. Vol. 1. São Paulo: FTD, 2016.

CEREJA, William; VIANNA, Carolina Dias; DAMIEN, Christiane. Português contemporâneo: diálogo, reflexão e uso. Vol. 1. São Paulo: Saraiva, 2016.

CHEVALLARD, Y. La transposición didácti$c a$ : del saber sabio al saber enseñado. Buenos Aires: Aique, 1991.

COLOMER, Teresa. Andar entre livros: a leitura literária na escola. São Paulo: Global, 2007.

COSSON, R. Letramento literário: teoria e prática. 2. ed. São Paulo: Contexto, 2018.

FARACO, Carlos Emílio; MOURA, Francisco Marto de; MARUXO JÚNIOR, José Hamilton. Língua Portuguesa: linguagem e interação. Vol. 1. 3. ed. São Paulo: Ática, 2016.

FARACO, Carlos Emílio. Português: língua e cultura. Vol. 1. 3. ed. Curitiba: Base Editorial, 2013.

FNDE. Dados estatísticos. Programas do livro. Brasília, 2017a. Disponível em: <http:// www.fnde.gov.br/programas/programas-do-livro/pnld/dados-estatisticos >. Acesso em: 6 abr. 2019. 
FNDE. Sobre os Programas do livro. Programas do livro. Brasília, 2017b. Disponível em: <http://www.fnde.gov.br/programas/ programas-do-livro/livro-didatico/guia-do-livro-didatico/item/11148-guia-pnld-2018>. Acesso em: 6 abr. 2019.

FRYE, Northrop. Anatomia da crítica. Tradução de Marcus De Martini. São Paulo: É Realizações, 2013.

GENETTE, Gérard. Introdução ao Arquitexto. Tradução de Cabral Martins. Organização de Maria Alzira Seixo. Lisboa: Vega, 1986.

JAEGER, Werner Wilhelm. Paidéia: a formação do homem grego. Tradução de Artur M. Parreira. 3. ed. São Paulo: Martins Fontes, 1994.

KAYSER, Wolfgang. Análise e interpretação da obra literária. Introdução à ciência da literatura. Coimbra: Armênio Amado, 1976.

MARASCHIN, Cleci. Conhecimento, escola e contemporaneidade. In: PELLANDA, Nize Maria Campos; PELLANDA, Eduardo Campos (Org.). Ciberespaço: um hipertexto com Pierre Lévy. Porto Alegre: Artes e Ofícios, 2000.

MATTA, Gabriel da. Livros escolares no Brasil durante os anos finais do Império e início da República (1870-1910). Ministério da Cultura: Fundação Biblioteca Nacional, 2010.

MILLER, Paul Allen. Lyric texts and lyric consciousness: the birth of a genre from Archaic Greece to Augustan Rome. London: Routledge, 1994.

MORAN, José Manuel. Como utilizar a Internet na educação. Ciência da Informação, Brasília, DF, v. 26, n. 2, p. 146-153, 1997.

ORMUNDO, Wilton; SINISCALCHI, Cristiane. Se liga na língua: literatura, produção de texto, linguagem. Vol. 1. São Paulo: Moderna, 2016.

PLATÃo. A República. Tradução de Maria Helena da Rocha Pereira. 9. ed. Lisboa: Fundação Calouste Gulbankian, 2001.
PLATÃO. A República. Tradução de Carlos Alberto Nunes. 3. ed. Belém: EDUFPA, 2000.

ROUXEL, A. Aspectos metodológicos do ensino da literatura. In: DALVI, M. A.; REZENDE, N. L. de, JOVER-FALEIROS, R. (Orgs.). Leitura de literatura na escola. São Paulo: Parábola, 2013. p. 17-33.

SILVA, Ivone Ribeiro et al. Português: trilhas e tramas. Vol. 1. 2. ed. São Paulo: Leya, 2016.

SNELL, Bruno. A cultura grega e as origens do pensamento europeu. São Paulo: Perspectiva, 2001.

SOARES, M. Português na escola - história de uma disciplina curricular. In: BAGNO, M. (Org.). Linguística da norma. São Paulo: Edições Loyola, 2004, p. 155-177. 